\title{
Phrenic nerve block, the rescue management for pneumothorax after retrolaminar block
}

\author{
Priyanka Mishra ${ }^{I^{*}}$, Praveen Talwar ${ }^{2}$, Nishith Govil', Prabakaran Parameswaran ${ }^{4}$ \\ Senior Resident ${ }^{l}$, Associate Professor ${ }^{2}$, Junior Resident ${ }^{4}$ \\ All India Institute of Medical Sciences, Uttarakhand, India.
}

\begin{abstract}
Retrolaminar block (RLB) has developed as a safer and easier alternative to paravertebral block (PVB). We hereby present a case of inadvertent complication of pneumothorax after administration of blind retrolaminar block. The detection of pneumothorax was made post-operatively by Point of Care Ultrasound (POCUS). Immediate rescue management was done by giving ipsilateral phrenic nerve block. The uplifting of diaphragm due to paralysis causes a reduction in chest volume, promoting the symphysis of two pleura and sealing of air leaks from lung. This appears to be an effective way to manage mild to moderate pneumothorax without intercostal chest tube drain (ICD) insertion.
\end{abstract}

Keywords: Phrenic nerve block; pneumothorax; retrolaminar block

\section{Introduction}

The advent of peripheral nerve blocks has revolutionised the realm of peri-operative analgesia. Retrolaminar block (RLB) has developed as an alternative to paravertebral block (PVB), considered to be a safer and easier technique. It still holds the risk of pneumothorax and inadvertent epidural or intrathecal drug administration.

\section{Case report}

A 52-year male patient, smoker, American Society of Anaesthesiologists (ASA) Grade II was scheduled for robotic assisted right nephrectomy. After attaching all standard monitors, under aseptic precautions, patient was administered retrolaminar block at $T_{12}$ space by inserting the needle $1 \mathrm{~cm}$ lateral to $\mathrm{T}_{12}$ spinous process and giving $20 \mathrm{ml}$ of $0.25 \%$ bupivacaine on lamina. Following this, patient was induced and maintained on volume control mode at low flow of $1 \mathrm{~L} / \mathrm{min}$. In lateral decubitus position, pneumoperitoneum was maintained on 14 $\mathrm{mmHg}$. Intraoperatively, there was a rise

*Correspondence: Priyanka Mishra

E mail: pmishra15390@gmail.com

https://orcid.org/0000-0002-1870-7923

Received: 31/10/2019

Accepted: 07/03/2020

DOI: http:/doi.org/10.4038/slja.v28i2.8516 in airway pressures (from $12 \mathrm{mmHg}$ to 18 $\mathrm{mmHg}$ ) and end tidal carbon dioxide tension $\left(\mathrm{EtCO}_{2}\right)$ from $34 \mathrm{mmHg}$ baseline to 42 $\mathrm{mmHg}$, that was managed by shifting to pressure control ventilation (PCV). After the completion of surgery, patient was reversed and extubated. However, post extubation, patient could not maintain oxygen saturation $\left(\mathrm{SpO}_{2}\right)$ above $90 \%$ on air $(96-97 \%$ on oxygen) though the haemodynamics were stable. On examination, air entry on the right side was considerably decreased. Possibility of pneumothorax was suspected and Point of Care Ultrasound (POCUS) was employed in operation theatre (OT). Pneumothorax was confirmed by presence of barcode sign. Decision of administering right phrenic nerve block was made. Under real time USG guidance, phrenic nerve was identified at the level of sixth cervical vertebra between anterior scalene and sternocleidomastoid muscle and a $22 \mathrm{G}$ catheter was inserted. The position of the catheter was confirmed by administration of one $\mathrm{ml}$ normal saline under direct USG guidance followed by a bolus of $20 \mathrm{ml} 0.5 \%$ bupivacaine. Effectivity of the block was confirmed 30 minutes later by absence of movement of right hemidiaphragm accompanied with an improvement in the oxygen saturation. Patient was then shifted to Intensive Care Unit (ICU) for further observation. $15 \mathrm{ml}$ of $0.25 \%$ bupivacaine was repeated six hours later under USG guidance. Subsequent evaluation revealed improvement in 
symptoms. USG evaluation twelve hours later showed persistence of pneumothorax and hence, we repeated another dose of $15 \mathrm{ml}$ of $0.25 \%$ bupivacaine for phrenic nerve block. X-ray chest after $24 \mathrm{hrs} \mathrm{showed}$ significant reduction of pneumothorax compared to immediate post-operative chest x-ray. (Image 1) Patient was shifted from ICU after $24 \mathrm{hrs}$ and discharged from hospital after five days with complete resolution of pneumothorax. (Image 2)

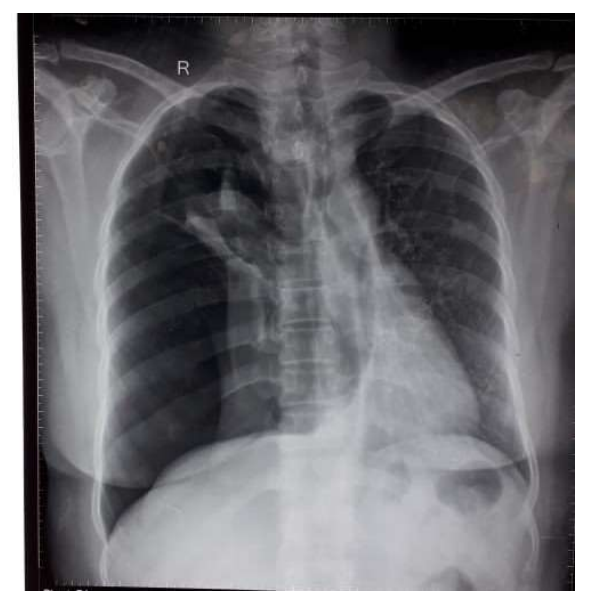

Image 1 - Immediate post-operative chest $\mathrm{X}$ ray showing right sided pneumothorax.

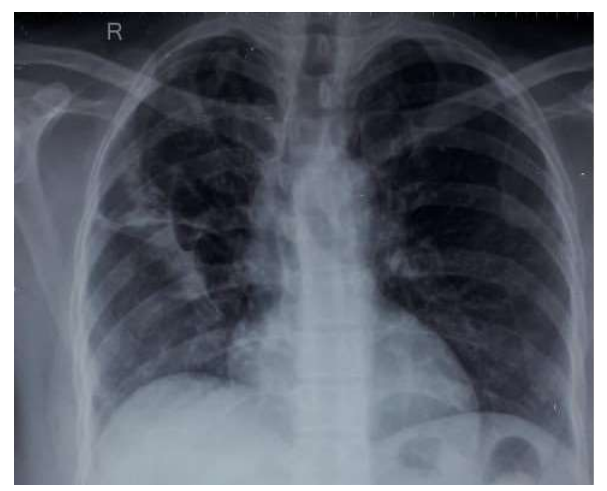

Image 2 - Resolved pneumothorax in chest radiograph $24 \mathrm{hr}$ after surgery.

\section{Discussion}

As the robotic laparoscopic surgeries are gaining popularity, anaesthetists need to be prepared to confront the challenges associated with them. In our case, we diagnosed pneumothorax post-operatively. Various causes of peri-operative pneumothorax include surgical injury to pleura, injury during upper extremity and truncal nerve blocks, barotrauma during mechanical ventilation, central venous cannulation and bulla rupture in an emphysematous patient during Positive Pressure Ventilation (PPV). Ruling out all the other causes, we narrowed our suspicion to bulla rupture as our patient was a chronic smoker who received PPV intra-operatively and the higher possibility of pleura puncture while administering the block. Retrolaminar block has emerged as an alternative to PV Band was first reported in $2006 .{ }^{1}$ The needle puncture site is taken $1-1.5 \mathrm{~cm}$ lateral to the target spinous process and proceeded until it contacts the lamina, followed by injecting $20-30 \mathrm{ml}$ of local anaesthetics on the lamina. ${ }^{2}$ In our case, we used blind landmark approach for giving RLB. There was some rise in airway pressures and $\mathrm{EtCO}_{2}$ intraoperatively, but we accounted it to the physiological changes associated with pneumoperitoneum and managed it using PCV. Inferiorly, the pleura reflects onto diaphragm above the costal margin and extends around the thoracic wall following eighth rib (midclavicular line), tenth rib (midaxillary line) and twelfth rib (also posterior vertebra of T12). ${ }^{3}$ As our patient was a chronic smoker, he might have had hyperinflation of lungs and resultant lower extension of pleura predisposing to pleural puncture. The pneumoperitoneum causes rise in $\mathrm{EtCO}_{2}$, peak inspiratory pressure and plateau pressure which further delayed the detection of pneumothorax. We could not detect pneumothorax till post extubation when the patient failed to maintain $\mathrm{SpO}_{2}$ above $90 \%$ on air. Intraoperative pneumothorax can worsen the physiological effects of pneumoperitoneum. ${ }^{4}$ Small pneumothorax may get resolved spontaneously and if large may require insertion of intercostal chest tube drain (ICD). Patella et al (2018) showed that phrenic nerve block was effective in reducing the residual pleural space post lung resection without requiring ICD. They advocated that paralyzing the diaphragm causes reduction in chest volume, promotes symphysis of two pleura and the sealing of air leaks from the lung. ${ }^{5}$ Our patient also responded to the phrenic nerve block and ICD insertion was not required. Phrenic nerve block appears to be successful in 
treating the inadvertent complication of pneumothorax that occurred after retrolaminar block. To the best of our knowledge, this is first of an article published about such an intervention for pneumothorax after a retrolaminar block. However, more research needs to be done on this to validate these results in a larger series for management of pneumothorax.

\section{References}

1. H. Ueshima and H. Otake. Similarities between the retrolaminar and erector spinae plane blocks. Regional Anesthesia and Pain Medicine. 2017; 42(1):123-124. https://doi.org/10.1097/AAP.000000000000 $\underline{0526}$

PMid:27997492

2. Eiko Onishi, Noriko Toda, Yoshinobu Kameyama, and Masanori Yamauchi. Comparison of Clinical Efficacy and Anatomical Investigation between Retrolaminar Block and Erector Spinae
Plane Block. BioMed Research International.2019;17:1-8.

https://doi.org/10.1155/2019/2578396 PMid:31032339 PMCid:PMC6458933

3. Goizueta AA, Bordoni B. Anatomy, Thorax, Lung Pleura and Mediastinum. Stat Pearls Treasure Island (FL).2019:1-4.

4. Leonard IE, Cunningham AJ. Anaesthetic considerations for laparoscopic cholecystectomy. Best Pract Res Clin Anaesthesiol. 2002;16:1-20.

https://doi.org/10.1053/bean.2001.0204 PMid:12491540

5. Patella M, Saporito A, Mongelli F, et al. Management of residual pleural space after lung resection: fully controllable paralysis of the diaphragm through continuous phrenic nerve block. J Thorac Dis. 2018;10 (8):4883-90.

https://doi.org/10.21037/jtd.2018.07.27

PMid:30233862 PMCid:PMC6129885 